\title{
Acute Hydrocephalus in an Adult Patient Secondary to Unruptured Arteriovenous Malformation
}

\author{
Benjamin S. Szewczyk ${ }^{1}$, Pouya Entezami ${ }^{1 *}$, Bruce I. Tranmer ${ }^{2}$ \\ ${ }^{1}$ Department of Neurosurgery, Albany Medical College, Albany, NY, USA \\ ${ }^{2}$ Department of Neurosurgery, Vermont Medical Center, Burlington, VT, USA
}

*Corresponding Author: Benjamin Szewczyk, Albany Medical Center, 47 New Scotland Ave, MC-10, Albany, NY 12208-3479.

Received Date: May 05, 2021; Accepted Date: May 10, 2021; Published Date; May 19, 2021

Citation: Benjamin S. Szewczyk, Entezami P, Bruce I. Tranmer. Acute Hydrocephalus in an Adult Patient Secondary to Unruptured Arteriovenous Malformation. J. Surg Case Repo and Imag. 4(4); DOI:10.31579/2690-1897/077

Copyright: () 2021 Benjamin Szewczyk, This is an open-access article distributed under the terms of the Creative Commons Attribution License, which permits unrestricted use, distribution, and reproduction in any medium, provided the original author and source are credited

\begin{abstract}
Acute hydrocephalus as a result of unruptured arteriovenous malformation (AVM) is a rare phenomenon in the adult population. Patients with AVMs typically present with hemorrhage, seizures, or focal neurologic deficits. Hydrocephalus may result from obstructing the native cerebrospinal fluid drainage by the malformation's architecture. We report a previously healthy 32 year-old male who initially presented to an optometrist with blurry vision, visual obscurations, and papilledema. A large right frontal cerebral AVM with hydrocephalus and papilledema was confirmed by MRI. Unfortunately localized lesions may result in hydrocephalus as a rare presentation in unruptured AVMs.
\end{abstract}

Key words: Arteriovenous malformation; Cerebrospinal fluid; Hydrocephalus

Running head: Acute Hydro from Unruptured AVM

\section{Introduction}

Arteriovenous malformations (AVM) frequently present with hemorrhage, headaches, seizures, and focal neurologic deficits. However, AVMs have rarely been reported to cause hydrocephalus or pseudotumor cerebri-like symptoms. ${ }^{1-12}$ The likelihood of causing obstructive hydrocephalus depends on the location of the nidus and draining veins, as well as flow dynamics. Symptomatology may arise from both the AVM itself (i.e., seizures, hemorrhage, headaches, focal deficits) as well as from hydrocephalus or pseudotumor syndromes (i.e. altered mental status, visual changes, gait disturbances, incontinence). The current study identifies a young male who presented in an unusual fashion for AVMs, with vision changes, headaches, and nausea secondary to hydrocephalus caused by to CSF obstruction by a draining vein.

\section{Case Presentation}

We present an otherwise healthy 32 year-old right-handed male evaluated at an outside hospital for 3-4 months of mild frontal headaches and blurred vision. He was originally seen by an optometrist with complaints of blurred vision and "gray spots" when moving from seated to standing position. Papilledema was noted on physical examination.

He was referred to an ophthalmologist who confirmed this finding and referred the patient to a Neurologist. Subsequent magnetic resonance imaging (MRI) revealed a large right frontal cerebral AVM measuring $5.6 \mathrm{~cm} \times 5.4 \mathrm{~cm} \times 4.4 \mathrm{~cm}$ (Figure 1). 

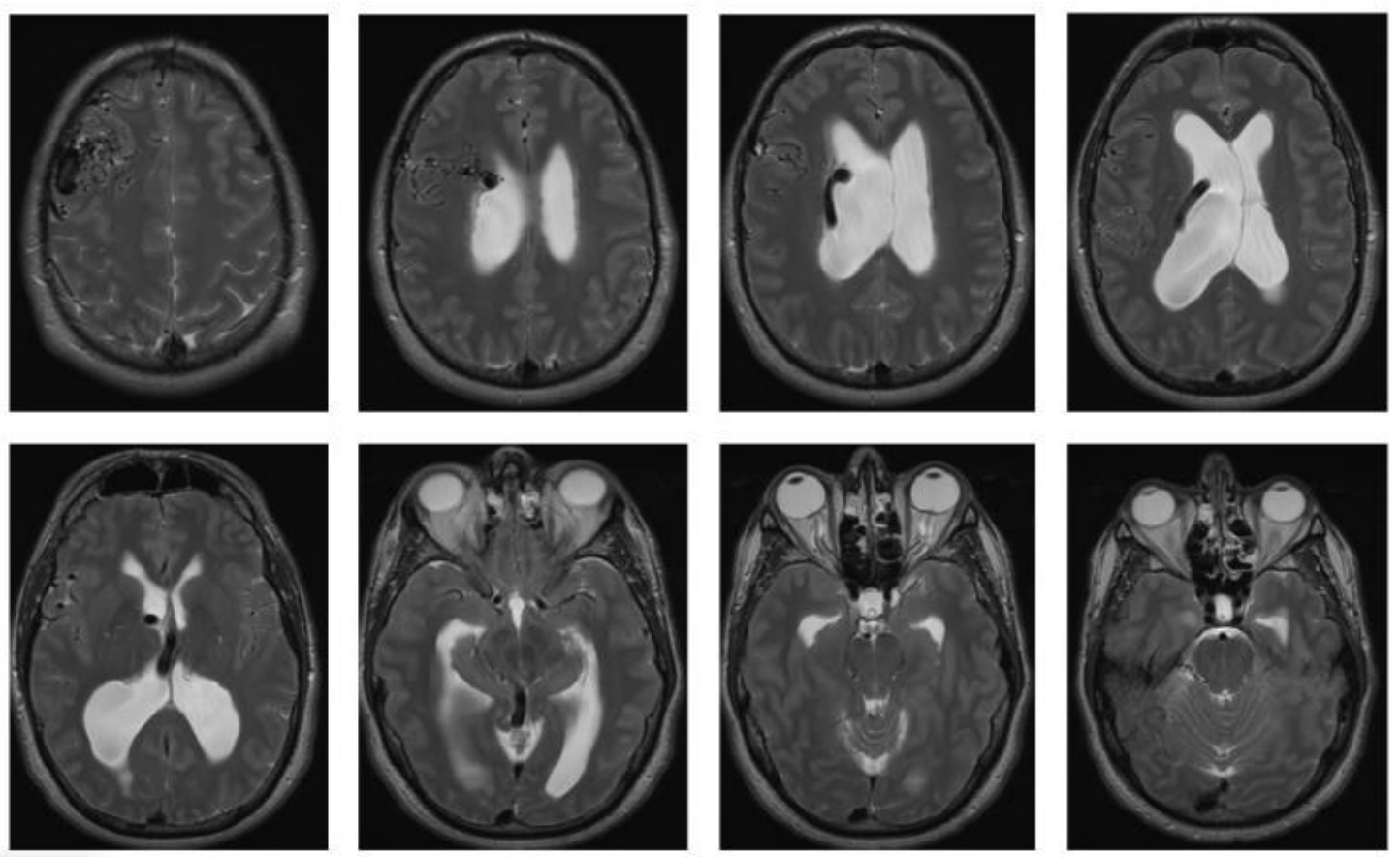

Figure 1: Serial axial T2 MRI demonstrating large right frontal AVM with hydrocephalus, demonstrating the path of the large draining vein through the right lateral ventricle, compressing the foramen of Monroe, and into the vein of Galen.

Arterial supply was predominantly from the right middle and anterior cerebral arteries, with primary drainage via a large draining vein measuring up to $8 \mathrm{~mm}$ and coursing across the right lateral ventricle. This vein abutted the foramen of Monroe before eventually emptying into the vein of Galen. There was marked dilation of the right lateral ventricle and a $6 \mathrm{~mm}$ midline shift with secondary dilation of the left lateral ventricle. Therefore it appeared as though this large draining vein was causing obstructive hydrocephalus.

He was transferred to a tertiary care center for neurosurgical evaluation.

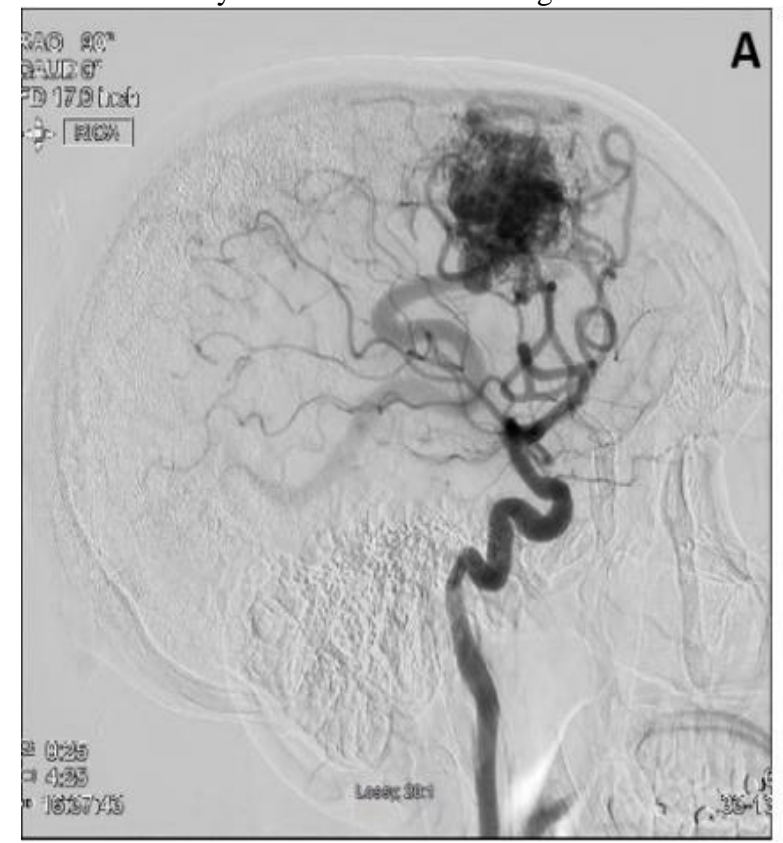

On arrival he was in no acute distress and grossly neurologically intact, with complaints of nausea. He underwent a computed tomography (CT) angiography of the head and neck, confirming a Spetzler-Martin grade IV (size $>6 \mathrm{~cm}$, non-eloquent brain, deep drainage) right frontal AVM. The next day the patient underwent a diagnostic cerebral angiogram revealing a small aneurysm at the bifurcation of the right $\mathrm{A} 2$ segment of the anterior cerebral artery and a large venous aneurysm along the lateral aspect of the nidus (Figures 2). Multi-staged embolization followed by a surgical resection of the nidus was planned for this patient.

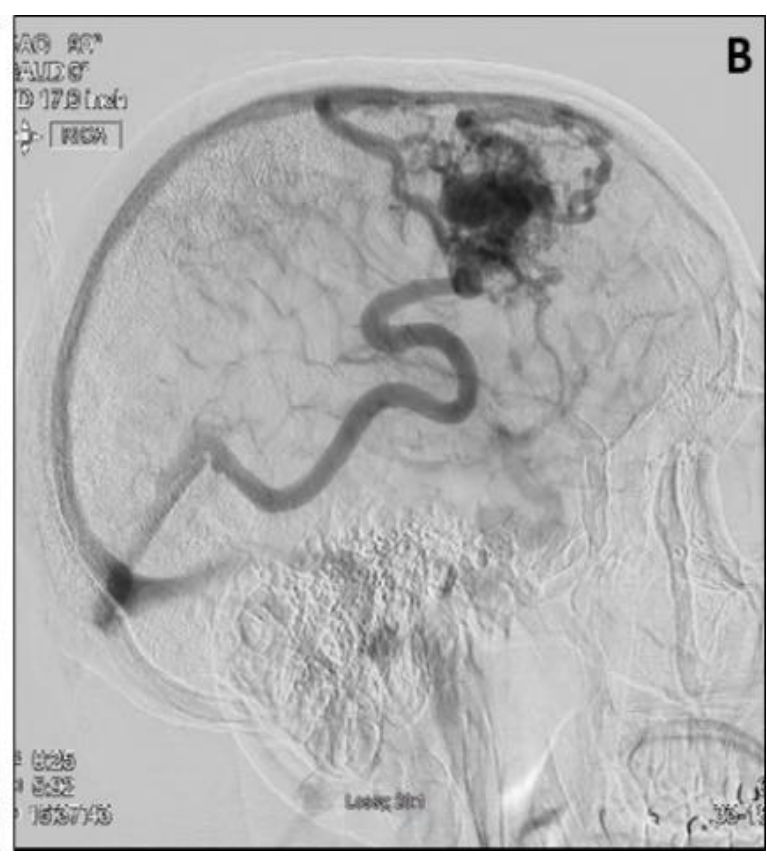

Figure 2: (A) Arterial and (B) venous phases of a diagnostic cerebral angiogram in the sagittal plane demonstrating a right frontal AVM (fed by the right middle cerebral artery and right anterior cerebral artery), with a large draining vein. 


\section{Discussion}

Acute symptomatic hydrocephalus secondary to unruptured AVMs in the adult population remains a very rare phenomenon. ${ }^{13}{ }^{14}$ Multiple mechanisms reported for the etiology of the hydrocephalus, including direct mechanical obstruction from draining vessels or the nidus itself, hydrodynamic disequilibrium, overproduction of CSF, and venous congestion. ${ }^{912} 1516$

Our patient originally presented with blurry vision and positiondependent visual obscurations in addition to papilledema. Visual changes due to unruptured AVMs are scarcely reported in the literature. Bayri et al. reported one such patient with visual loss as a result of and unruptured AVM, interestingly with a very similar location and drainage to our case report. ${ }^{4}$ Their patient was treated with cerebrospinal fluid (CSF) diversion followed by radiosurgery.

Treatment modalities for hydrocephalus secondary to unruptured AVMs may vary and there are several factors to consider. CSF diversion can be achieved by shunting, endoscopic third ventriculostomy (ETV), septostomy, extraventricular drainage (EVD) during surgical treatment, or close observation if minimally symptomatic. Invasive procedures such as EVD placement or ETV carry additional risk of damage to draining vessels. This can result in intraventricular hemorrhage, especially in the case presented where the large draining vein traversed the right ventricle and compressed the foramen of Monroe. AVM location and drainage may determine the best modality for treatment.

\section{Conclusions}

Acute hydrocephalus secondary to unruptured AVMs remains a rare phenomenon in the adult population. Unfortunately localized lesions may result in this uncommon presentation, as with this patient.

\section{References}

1. Pribil S, Boone SC, Waley R. (1983). Obstructive hydrocephalus at the anterior third ventricle caused by dilated veins from an arteriovenous malformation. Surg Neurol; 20(6):487-92.

2. Rodriguez Rodriguez R, Molet Teixido J. (2013). Letter to the Editor of Acta Neurochirurgica: Obstructive hydrocephalus caused by unruptured arteriovenous malformation treated with endoscopic third ventriculostomy. Acta Neurochir (Wien);155(5):901-2.

3. Tucker A, Tamura Y, Hanabusa K, et al. (2013). Endoscopic third ventriculostomy for hydrocephalus due to unruptured pineal AVM: case report and review of the literature. J Neurol Surg A Cent Eur Neurosurg;74.
4. Bayri Y, Sakar M, Ozen A, et al. (2017). Drainage Vein Induced Hydrocephalus Caused by an Unruptured Arteriovenous Malformation in an Adult Presenting with Visual Loss. Turk Neurosurg;27(1):151-54.

5. Champeaux C, Botella C, Lefevre E, et al. (2018). Obstructive Hydrocephalus Caused by an Unruptured Arteriovenous Malformation Successfully Treated by Endoscopic Third Ventriculostomy After Shunt Dysfunction. Turk Neurosurg;28(3):500-04.

6. David CA, Peerless SJ. (1995). Pseudotumor syndrome resulting from a cerebral arteriovenous malformation: case report. Neurosurgery;36(3):588-90.

7. Kamite Y, Akimithu T, Ohta K, et al. (1994). A case of intracranial arteriovenous malformation presenting with intracranial hypertension. No Shinkei Geka;22(5):485-489.

8. Esparza J, Lobato RD, Munoz MJ, et al. (1981). Giant cerebral arteriovenous malformation producing a noncommunicating hydrocephalus. Surg Neurol;15(1):76-80.

9. Geibprasert S, Pereira V, Krings T, et al.(2009). Hydrocephalus in unruptured brain arteriovenous malformations: pathomechanical considerations, therapeutic implications, and clinical course. J Neurosurg;110(3):500-507.

10. Mindea SA, Yang BP, Batjer HH. (2007). Unruptured arteriovenous malformation in a patient presenting with obstructive hydrocephalus. Case report and review of the literature. Neurosurg Focus;22(4):E11.

11. Ono K, Oishi H, Suga Y, et al. (2015). Case Report of Cerebellar Vermis Arteriovenous Malformation Presenting with Hydrocephalus due to Aqueductal Stenosis. No Shinkei Geka;43(9):843-848.

12. DeFeo DR, Kusske JA, Rush JL, et al. (1976) Aqueductal occlusion by midline arteriovenous malformation. Surg Neurol;5(1):5.9-62.

13. Hoi S, Kerber C. (1983). Ventricular obstruction secondary to vascular malformations. Neurosurgery;12(5):572-5.

14. Lobato RD, Lamas E, Cordobes F, et al. (1980). Chronic adult hydrocephalus due to uncommon causes. Acta Neurochir (Wien);55(1-2):85-97.

15. Ebinu JO, Matouk CC, Wallace MC, et al. (2011). Hydrocephalus secondary to hydrodynamic disequilibrium in an adult patient with a choroidal-type arteriovenous malformation. Interv Neuroradiol; $17(2): 212-216$.

16. Carleton CC, Cauthen JC. (1975). Vascular ("arteriovenous") malformations of the choroid plexus. Arch Pathol;99(5):286-8.
This work is licensed under Creative Commons Attribution 4.0 License

To Submit Your Article Click Here: Submit Manuscript

DOI: $10.31579 / 2690-1897 / 077$
Ready to submit your research? Choose Auctores and benefit from:

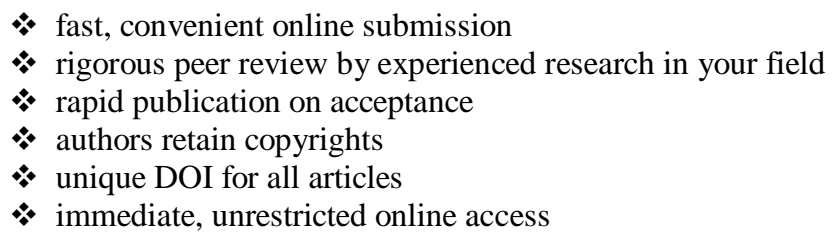

At Auctores, research is always in progress.

Learn more www.auctoresonline.org/journals/journal-of-surgical-casereports-and-images- 